\title{
O DEVIR PÚBLICO DA HISTÓRIA NO TEMPO PRESENTE: OUTRAS LINGUAGENS, OUTRAS NARRATIVAS
}

\author{
Ricardo Santhiago' \\ Viviane Trindade Borges 2 \\ Rogério Rosa Rodrigues ${ }^{3}$
}

\begin{abstract}
Resumo
O presente artigo problematiza o métier do historiador a partir da história pública e da história do tempo presente. Parte-se do pressuposto de que todo conhecimento histórico é produzido em diálogo com os problemas e questões do presente, mas que a noção de demanda social instiga a pensar mais diretamente sobre a relação entre a sociedade e os temas, posicionamentos e formas de atuação da comunidade de historiadores. Analisamse alguns casos recentes em que historiadores problematizaram questões latentes da atualidade e enfrentaram o desafio de adaptar sua formação em construção de narrativas em linguagens e suportes não usuais.
\end{abstract}

Palavras-chave: História Pública; História do Tempo Presente; Demanda social.

\begin{abstract}
This article discusses the historian's craft from the perspectives of public history and history of the present. It assumes that all historical knowledge is produced in dialogue with the problems and issues of the present, but that the notion of social demand urges a more intense discussion about the relationship between the society and, on the other side, the themes, stances, and forms of action adopted by historians. The article analyzes a few recent cases in which historians felt compelled to problematize latent issues of the present time and faced the challenge of adapting their training in the construction of narratives about the past through unusual means.
\end{abstract}

Keywords: Public History; History of the Present; Social demands.

\footnotetext{
${ }^{1}$ Historiador e comunicólogo, é professor da Universidade Federal de São Paulo (Unifesp). Graduado em Jornalismo (PUC-SP, 2004), com especialização em Jornalismo Científico (Unicamp, 2006); mestre e doutor em História Social (USP, 2009/2013), com pós-doutorado em História (UFF, 2015). Seu trabalho interdisciplinar concentra-se nas áreas de história pública e história oral, comunicações e artes, teoria e metodologia de pesquisa. E-mail: rsanthiagoc@gmail.com

2 Doutora em História pela Universidade Federal do Rio Grande do Sul (UFRGS). Professora do Departamento de História e Programa de Pós-Graduação em História da Universidade do Estado de Santa Catarina (UDESC). E-mail: vivianetborges@gmail.com

${ }^{3}$ Doutor em História. Professor de Teoria e Metodologia da História da Universidade do Estado de Santa Catarina (UDESC), Professor credenciado no Programa de Pós-Graduação em História e no Mestrado Profissional em Ensino de História da UDESC. E-mail: rogerclio@gmail.com
} 


\section{Outras linguagens, outras narrativas}

Como se comporta o historiador ao ver-se na condição de pesquisador e testemunha dos acontecimentos? Que papel desempenha quando se vê obrigado a somar, à atividade usual do debate entre os pares, o diálogo direto com as questões e os sujeitos do seu tempo? Que riscos corre ao se posicionar no e sobre o tempo vivido? Esse risco é tão somente individual, proporcional à investida de um certo historiador, ou atinge toda a comunidade de historiadores e a própria disciplina histórica? A decisão de falar para fora da academia é tão somente uma decisão pessoal ou é um imperativo que responde a demandas sociais em momentos de crise? É possível resguardar os critérios que balizam a atividade do historiador diante das exigências e implicações da história pública e da história do tempo presente? A própria formulação dessas muitas perguntas remete a inquietações profissionais do nosso tempo, lançadas pela comunidade de historiadoras e historiadores, pelas novas gerações de alunos e alunas, pelas diferentes mídias, cada vez mais presentes em nosso cotidiano.

Questionamentos como estes - sobre os papéis sociais que o historiador assume e desempenha - têm sido enfrentados por inúmeros autores nas últimas décadas, em trabalhos instigantes que têm a relação entre a história e a vida pública como tema e como norte, a partir de diferentes contextos nacionais. Em uma variedade de abordagens, eles defendem a cultura humanística contra o economicismo dogmático que pervade muitas leituras do social ${ }^{4}$, contendem a interpretação de que a especialização e a profissionalização da História teriam encaminhado a uma alegada irrelevância pública da disciplina ${ }^{5}$, insistem na contribuição da perspectiva histórica como um modo distintivo de pensar o presente ${ }^{6}$, interpelam a própria comunidade de historiadores sobre o "curto-prazismo" da disciplina ao entender a longa duração como o horizonte temporal com forte orientação ao futuro ${ }^{7}$, ou mesmo problematizam a risco de um presentismo que mais confunde a intervenção do historiador, que amplia seus horizontes de atuação ${ }^{8}$.

\footnotetext{
${ }^{4}$ BELAVICQUA, Piero (org.) A che serve la storia? I saperi umanistici alla prova della modernità. Roma: Donzelli Editore, 2011.

5 TYRRELL, Ian. Historians in Public: The Practice of American History, 1890-1970. Chicago / London: The University of Chicago Press, 2005.

${ }^{6}$ TOSH, John. Why History Matters. New York: Palgrave Macmillan, 2008.

${ }^{7}$ GULDI, Jo; ARMiTAGE, David. The History Manifesto. Cambridge: Cambridge University Press, 2014.

${ }^{8}$ HARTOG, François. Regimes de historicidade: presentismo e experiências do tempo. Belo Horizonte: Autêntica, 2013.
} 
Questões como essas também fizeram parte do retrato desenhado pelo historiador francês Olivier Dumoulin em livro lançado no Brasil sob o título O papel social do historiador: Da cátedra ao tribunal (2017). Nele, o autor faz uma refinada genealogia dos diversos papéis sociais desempenhados pelo historiador do final do século XIX ao final do século XX. Tomando como referência esse período, inventaria a emergência do historiador imparcial, passando pelo historiador patriótico, o engajado, o científico, o autoral e o taumaturgo. Mas é sobre uma modalidade específica que Dumoulin se detém: o que chama de historiador expert, aquele convocado como testemunha de episódios do passado, financiado por grandes empresas ou contratado pelo estado ou outras instituições para fornecer pareceres técnicos em querelas judiciais ou demandas sociais de seu tempo. É nessa categoria que Dumoulin inscreve não somente a emergência da história pública norte-americana (de fato, capitaneada em seus primeiros tempos pelo historiador Robert Kelley, consultor e perito especializado em diversos casos ligados a direitos aquíferos no estado da Califórnia) como também a modalidade da história do tempo presente francesa. Seu diagnóstico sobre os rumos do papel social do historiador está articulado com o avanço dessas duas áreas. Afirma o pesquisador:

A intervenção do historiador não se distingue mais da dos outros "profissionais" no sentido norte-americano da palavra: advogados, consultores, médicos preparam a ação mais do que a executam. Essa reificação da arte do historiador em produto mercantil alinha, portanto, seu papel com o de numerosos atores sociais que continuam nostalgicamente a batizar de arte o que não é mais hoje senão um serviço retribuído, como a medicina e a advocacia ${ }^{9}$.

Se lido a contrapelo, o diagnóstico de Dumoulin mostra que o apego nostálgico a uma história pela história pertence também aos que temem pelo desmoronamento das fronteiras disciplinares, as novas modalidades de ação e de consciência histórica. As últimas palavras do seu livro são:

Inegavelmente, os papéis que o historiador pode assumir dependem das oportunidades que o jogo social abre para ele. Mas a evolução das sociedades europeias rumo ao sistema norte-americano talvez seja acompanhada pela sagração de um novo papel para o historiador, uma consagração em que o autor dessas linhas se recusa de antemão a se reconhecer. Depois do escritor de história, depois do professor cientista, depois do pesquisador virá talvez o tempo do técnico da história ${ }^{10}$.

\footnotetext{
9 DUMOULIN, Olivier. O papel social do historiador. Da cátedra ao tribunal. Belo Horizonte: Autêntica, 2017.

10 DUMOULIN, Olivier. O papel social do historiador. Da cátedra ao tribunal. Belo Horizonte: Autêntica, 2017.
} 
A vertente norte-americana da história pública é vista por Dumoulin como uma espécie de protótipo de uma tendência da historiografia europeia. $\mathrm{O}$ tom do texto por vezes resvala em certo desdém pela história pública, atrelando-a indissociavelmente à perda do domínio do conhecimento e à sua mercantilização no mercado dos bens simbólicos e econômicos do mundo contemporâneo. O autor não considera, no entanto, que muitos dos debates propostos pelos historiadores do tempo presente têm sido explorados pelos historiadores públicos, dada a imbricação entre essas duas perspectivas ${ }^{11}$. As potencialidades da História do Tempo Presente e da história pública, aliás, não se reduzem a essa dimensão.

A noção de "demanda social" 12 , a nosso ver, coloca em pauta mais diretamente os mecanismos pelos quais elementos do presente podem vir a orientar, em maior ou menor medida, questões elaboradas por uma comunidade profissional - no caso, os historiadores -, seus temas, posicionamentos e formas de atuação. Nessa perspectiva, a demanda social inverte a lógica da produção do conhecimento em uma ciência que tem como matéria a história dos homens no tempo: em vez de ser uma reflexão gerada a frio, no âmbito da oficina do historiador, com seus aportes teóricos e metodológicos em primeiro plano - ainda que sem desprezar suas posturas políticas e ideológicas - tratase de uma história que nasce do vínculo direto com o presente e sobre os conflitos em jogo no presente.

Mais do que em diálogo com o tempo de atuação profissional do historiador, uma história demandada pela sociedade seria aquela pautada pelo presente, e objeto de um intrincado controle social: vigiada por um público que inclui não apenas os pares historiadores, como os colegas acadêmicos de áreas afins, mas também, e talvez, principalmente, um público amplo e heterogêneo. São leitores leigos, donas de casa, jovens estudantes secundaristas, militantes de movimentos sociais com ou sem vínculo direto com o mundo acadêmico, etc. Em síntese, uma comunidade ampliada de consumidores que usam - ou estão em condições de usar - os meios de comunicação, principalmente as redes sociais, para levantar pautas e se manifestar sobre a produção dos historiadores.

\footnotetext{
${ }^{11}$ SANTHIAGO, Ricardo. "História pública e autorreflexividade: da prescrição ao processo". Tempo e Argumento, Florianópolis, v. 10, n. 23, p. 286 - 309, jan./mar. 2018.

${ }^{12}$ Ver: SAUVAGE, Pierre. "Uma historia del tempo presente". Historia Critica, n. 17, p. 59-70, 1998; FERREIRA, Marieta de Moraes. "Demandas sociais e a história do tempo presente". In: Varella, F. et al. (org.) Tempo presente \& usos do passado. Rio de Janeiro: Ed. FGV, 2012. p. 101-124 e DELGADO, Lucilia de Almeida Neves; FERREIRA, Marieta de Moraes. "História do tempo presente e ensino de História". História Hoje, v. 2, n. 4, p. 19-34, 2013.
} 
Quando atentos a essas demandas, historiadores experimentam organizar seus argumentos em formatos e linguagens adequados ao meio no qual se manifestam. Obrigam-se a uma criatividade, adaptação e lógica de argumentação distintos dos modelos predominantes nos quais o historiador tende a obter formação. A monografia ou o artigo acadêmico, assim, deixam de ser os formatos por excelência de socialização do saber histórico. ${ }^{13}$ Constroem narrativas que, embora conhecendo-as, escapam às normas acadêmicas, com críticas organizadas por lógicas alheias a estruturação do discurso, do vocabulário e mesmo do estilo historiográfico.

Diante disso, uma pergunta cabível é: aquilo que resta da narrativa do historiador produzida diante dessas demandas sociais (isto é, narrativas sem notas de rodapé, sem longas contextualizações, na impossibilidade, em alguns casos, de comportar um exaustivo apanhado historiográfico) permanece sendo história? A partir desse devir da história pública e da história do tempo presente, pode ter lugar inclusive uma reinvenção da história e do papel social do historiador em uma modalidade que não apenas recupere sua conexão com a ciência, a arte e a sociedade, como também seja mais aberta e democrática em seus modos de fazer e de agir.

Com essas questões em mente, analisaremos alguns exemplos atuais da presença de historiadores junto às demandas sociais do nosso tempo, restringindo-nos ao contexto brasileiro recente. Elegemos casos que incluem uma narrativa ficcional, uma paródia musical, a composição de um samba enredo e a apropriação de um método de pesquisa narrativa. Embora cada um desses quatro casos envolva uma estrutura própria, é preciso destacar que graças às redes sociais o acesso a materiais produzidos nesses e em outros formatos popularizam-se em escala temporal e espacial impressionante. Com isso, promovem debates que vão da simples opinião à tentativa de conferir sentido ao material produzido, seja por meio de outros textos, seja por meio de comentários em timelines. Nos casos levantados, historiadores e historiadoras não se furtaram a essa discussão: mais do que refletir sobre essas novas estruturas de apresentação das narrativas históricas, eles participaram como compositores e intérpretes das mesmas.

\footnotetext{
${ }^{13}$ Uma das chaves, entre outras possíveis, para a leitura das diferentes linguagens e formatos explorados pelos historiadores que se dirigem ao grande público é a "divulgação de história". Para mais informações, ver: Carvalho \& Teixeira, 2019.
} 


\section{Chalhoub, historiador e cronista da terra Bruzundanga}

Tratemos de nosso primeiro caso. Leitor e pesquisador de Machado de Assis e de Lima Barreto, o historiador Sidney Chalhoub é professor aposentado da Unicamp e atualmente professor convidado na Universidade de Harvard nos Estados Unidos. Foi de além-mar que enviou alguns textos de análise de conjuntura para o blog Conversa de Historiadoras. ${ }^{14}$ Entre eles, um que intitulou Desfaçatez de Classe. ${ }^{15} \mathrm{O}$ narrador é um alter ego de Brás Cubas. Ele faz uma crônica sobre o episódio da prisão coercitiva de um "ex-presidente da república" do Bruzundanga por "um certo juiz da roça", episódio que aconteceu "nos remotíssimos dias de março de 2016", mais precisamente "no quarto dia daquele mês, sexta-feira aziaga". Afirma o narrador, antecipando o futuro, que "o acontecimento espetacular acelerou a história". ${ }^{16}$

Por meio da familiaridade que tem com a obra de Machado e de Barreto, Chalhoub usa e abusa do anacronismo para fazer uma reflexão complexa e bem humorada que salta nos tempos, tal qual o tigre benjaminiano, expresso em suas teses ao se referir ao modo como um autêntico historiador materialista deveria se portar diante dos tempos históricos. Na crônica o ilustre escritor brasileiro é apresentado como intérprete do Brasil, ou nas palavras do narrador, como: "Autor genial e complexo, Machado de Assis só teorizava por meio de alegorias, ou por linhas tortas, que é um jeito mais simples de dizer a mesma cousa. Por isso inventou Brás Cubas, outro guapo da história pátria, narrador e protagonista das Memórias." É como se Memórias Póstumas de Brás Cubas fosse não só um tratado sociológico do século XIX, mas guardasse em sua estrutura elementos capazes de nos fazer compreender os acontecimentos de 2016 e, por que não, antecipar o contexto complexo da campanha eleitoral de 2018.

Nas páginas de Memórias Póstumas de Brás Cubas o autor parece ter encontrado uma categoria capaz de explicar os acontecimentos presentes: descaramento ou desfaçatez de classe, um conceito cunhado para expressar momentos em que determinadas classes se sentem autorizadas a pronunciar os mais elevados impropérios,

\footnotetext{
${ }^{14} \mathrm{O}$ blog está disponível em: https://conversadehistoriadoras.com. Acesso em: 23 mai. 2019.

$15 \mathrm{O}$ texto completo pode ser acessado em: https://conversadehistoriadoras.com/2016/03/25/desfacatezde-classe-sidney-chalhoub/. Acesso em: 23 mai. 2019.

16 Todas as citações de Desfaçatez de classe foram retiradas do texto publicado no blog e disponível em: https://conversadehistoriadoras.com/2016/03/25/desfacatez-de-classe-sidney-chalhoub/ Acesso em: 25 mai. 2019
} 
pois devido a sua autoconfiança se sentem livres de qualquer punição, jurídica ou mesmo social.

Preconceitos raciais, de gênero e de classe, aqueles que poderiam acabar com a carreira, ou mesmo levar a prisão de quem os pronunciasse, são ditos sem nenhum constrangimento em tempos de desfaçatez de classe, reabrindo um portal do tempo que permite trazer para o presente estruturas de pensamento própria de séculos passados. Tudo isso sem nenhum constrangimento ou punição. Como o texto de Chalhoub entrevê, essa temporalidade se abre de quando em vez. Ela esteve presente no tempo de Braz Cubas e reapareceu em 2016. Vejamos como ela se manifestou lá e cá.

No universo escravista do século XIX a desfaçatez de classe pode ser apreendida historicamente a partir do momento que Braz Cubas se manifesta, sem nenhum pudor, ao referir-se ao escravizado Prudêncio como "o meu cavalo de todos os dias", ou quando pôs-se a refletir sobre a existência de Dona Plácida chegando à seguinte conclusão:

[ela veio ao mundo] "para queimar os dedos nos tachos, os olhos na costura, comer mal, ou não comer, andar de um lado para outro, na faina, adoecendo e sarando, com o fim de tornar a adoecer e sarar outra vez, triste agora, logo desesperada, amanhã resignada, mas sempre com as mãos no tacho e os olhos na costura, até acabar um dia na lama ou no hospital. ${ }^{17}$

De acordo com o narrador:

A desfaçatez de classe acontece quando a classe brascúbica, uma vez achacada de crise de despudor, como ocorreu na Bruzundanga naquelas memoráveis Jornadas de março de 2016, destampa ao mundo os mais recônditos segredos de sua maneira de ver as cousas, segundo a qual negros, mulheres e pobres existem para ralar ou empurrar traquitanas enquanto o patronato chiquérrimo vocifera, à beira-mar, contra a presidenta eleita. ${ }^{18}$

Seria o mesmo excesso de confiança, ou desfaçatez de classe, que levou um Brás Cubas reencarnado a declarar publicamente em 2016 que "analfabeto não pode ser ministro". Descendentes do defunto autor, que foi Cubas, não se constrangem em tornar público seus pensamento, agora não mais na forma de um livro póstumo, mas em timelines de redes sociais, tal como uma socialite que se referiu à filha adotiva de um casal de famosos como uma "macaca", ${ }^{19}$ ou uma certa advogada, que em vídeo esbraveja por ter que dividir o seu voo com empregadas domésticas e trabalhadores braçais. Ou ainda, a esposa de um famoso humorista, que, ao afirmar que "aeroporto

\footnotetext{
${ }^{17}$ Disponível em: https://conversadehistoriadoras.com/2016/03/25/desfacatez-de-classe-sidney-chalhoub/. Acesso em: 27 mai. 2019.

${ }^{18}$ Disponível em: https://conversadehistoriadoras.com/2016/03/25/desfacatez-de-classe-sidney-chalhoub/ Acesso em: 27 mai. 2019.

19 Disponível em: https://oglobo.globo.com/rio/filha-de-giovanna-ewbank-bruno-gagliasso-vitima-deracismo-22117146. Acesso em 23 ago. 2019.
} 
está parecendo rodoviária", se ressentiu por ter dividido o voo com um "cara (...) de bermuda e chinelo", indo do Rio de Janeiro para São Paulo. ${ }^{20} \mathrm{O}$ portal para o século XIX foi aberto e a desfaçatez de classe não é mais pronunciada por um defunto autor, mas por sujeitos defuntos, espécies de reencarnações de Brás Cubas.

Nesse texto, Sidney Chalhoub mobiliza todo o aporte profissional alcançado por ele como professor e pesquisador de história: erudição, pesquisa documental, preocupação com categorias históricas, organização argumentativa. Esses predicados já seriam suficientes para reconhecer esta crônica como uma montagem feita por um historiador profissional. Mas o autor acrescenta outras habilidades para além das que comumente definem esse ofício: domínio da narrativa, brincadeira com o anacronismo, posicionamento ético-político, uso da história para pensar o tempo presente. Das fronteiras da sua especialização em história da escravidão brasileira no século XIX, Chalhoub salta para o século XXI e produz um texto capaz de atingir não somente os novos historiadores, como uma nova geração de leitores, dentro e fora do ofício que nos toca. Para além disso, o texto tem implicações na própria operação historiográfica, visto que faz uso de procedimentos caros ao trabalho do pesquisador, mas inova na linguagem e no estilo.

O autor abriu o presente às múltiplas temporalidades, fazendo uma análise que é ao mesmo tempo conjuntural e estrutural. Sua análise foi capaz de penetrar nas singularidades econômicas e políticas do Brasil, mas também de revelar como a crise política e econômica interna se situava nos jogos bio-econômicos internacionais. Sua análise não tem nada de imparcial. Ele se posiciona claramente sobre o caso em questão, escancarando as contradições políticas e até morais daqueles que acusavam a então presidenta. Dessa forma, também revela seu posicionamento cidadão. O historiador se apresenta como profissional e como testemunho de um tempo. Testemunho que não se abriga trincheira de uma suposta imparcialidade política ou profissional, mas que se lança no campo de batalhas narrativas sobre nosso tempo, levando consigo equipamento próprio de sua formação como historiador.

20 Disponível em: https://www.correio24horas.com.br/noticia/nid/esposa-de-renato-aragao-reclama-deaeroporto-parece-rodoviaria/. Acesso em 20 set. 2019. 


\section{O Fado da Ursal}

Em que pese as inovações da crônica de Chalhoub, ela se manteve dentro de um formato razoavelmente familiar ao historiador: o de um texto estruturado em diversos parágrafos, com apresentação de uma ideia, argumentos, citações, desenvolvimento e conclusão. O segundo caso que apresentamos agora tem como singularidade o de ser uma paródia musical, que aproveita a estrutura de um texto musical anterior, alterandoo, e ativando assim o caráter contestatório provocado por esse deslocamento de sentido.

Está consagrada entre os historiadores a adoção da música como objeto e seu uso como fonte histórica, mas não tanto como forma de expressão. $\mathrm{O}$ acesso a esse recurso depende de outros predicados: conhecimento da linguagem e da notação musical, domínio de instrumentos, expressividade vocal, capacidade de compor. Historiadores que analisam música já os temos, trilhando o caminho aberto por pioneiros como Arnaldo Daraya Contier ${ }^{21}$ na busca de leituras interdisciplinares da música como fonte para a História. Historiadores/intérpretes o temos em escala menor, merecendo registro a atuação da professora e pesquisadora Miriam Hermeto com seus repertórios apresentados em formato de "aulas-show" multimídia, sobre os tempos da ditadura ou sobre os ecos de 1968. ${ }^{22}$ Mencione-se, fora do Brasil, o caso de Michael Frisch e sua 198 String Band, que apresenta espetáculos musicais, com intervenções audiovisuais e falas, sobre o repertório de folk music produzido durante a Grande Depressão por autores como Woody Guthrie. ${ }^{23}$ Aqui, apontamos para uma modalidade mais rara: a de historiador intérprete e compositor.

Nosso objeto de análise são as criações parodísticas apresentadas entre março de 2016 e outubro de 2019 na página "Paródia da Semana", disponível no Facebook. Tratou-se de um projeto desenvolvido por Rafael Rosa Hagemeyer, docente da Universidade do Estado de Santa Catarina, professor de história da música e produção de audiovisual vinculado ao Laboratório de Imagem e Som (LIS). Historiador com formação musical, foi também músico profissional em bares de Curitiba e Porto Alegre. Com a "Paródia da Semana", Hagemeyer somou aos seus trabalhos relacionados à resistência estudantil, a análise fílmica e musical, difundidos por meio de formatos

\footnotetext{
${ }^{21}$ Ver, a esse respeito: Moraes \& Lima, 2007.

${ }^{22}$ Alguns dos espetáculos apresentados por Hermeto são a aula show "meia oito" e "Na carreira" (concebidas por ela e Ricardo Frei). Ver, a respeito: Hermeto \& Lima, 2008.

${ }^{23}$ A esse respeito, ver o podcast "Folk Music as Oral History", produzido pelo Centro de História Oral da Columbia University: https://podcasts.apple.com/us/podcast/michael-frisch-198-string-band-folk-musicas-oral-history/id505159853?i=1000122211968.
} 
convencionais como o livro e o artigo acadêmicos, um novo caminho de atuação com a composição de paródias relacionadas a episódios políticos. Essas paródias são interpretadas por ele em formato voz e violão e gravadas em vídeos, nos quais o historiador é acompanhado por objetos lúdicos ou por projeções de imagens, ao fundo. Na página do projeto, Hagemeyer explica:

Considero esse projeto uma experiência que tem possibilitado perceber como as pessoas reagem a determinada interpretação de fatos, personagens e seu contexto. É sua leitura do contexto em que vivemos, considerando que a alegoria possui um poder ambíguo, pode mistificar ou revelar aspectos da realidade que não enxergamos envolvidos no turbilhão dos acontecimentos. É uma forma de narrar a história do tempo presente. ${ }^{24}$

Instigados pelo trabalho de Hagemeyer e por sua forma de enunciá-lo, entendemos a relevância de refletir sobre a seguinte questão-problema: a formação como historiador, para além de seu posicionamento ideológico, é articulada em suas composições paródicas? Para responder essa questão propomos uma análise de uma de suas paródias mais acessadas nas redes sociais: o Fado da Ursal.

\section{FADO DA URSAL}

Oh, musa de Bolívar

Oh, minha grande URSAL

Que surge num debate

Presidencial

Esquece a esquerda ingrata

Que já se corrompeu

E que só faz deboche

Do sonho que perdeu

$\mathrm{Ai}$, esta terra ainda vai cumprir seu ideal

Ainda vai juntar-se numa grande Ursal!

Sabes, no fundo eu sou um comunista...

Todos nós bolivarianos queremos toda América Unida

(Sem os Estados Unidos, é claro!)

Mesmo quando meu partido só está preocupado

Em conciliar, se aliar, reformar

Meu coração revolucionário fecha os olhos

E sinceramente arde..

Com Salvador Allende

Sandino e Che Guevara

Fidel e Marighela

\footnotetext{
${ }^{24}$ Disponível em: https://www.facebook.com/pg/parodiadasemana/about/?ref=page internal. Acesso em: 23 ago. 2019.
} 
A força de Zapata

Abolindo as fronteiras

Numa só grande pátria

O imperialismo ianque

Finalmente se acaba!25

A chamada "União Revolucionária Socialista da América Latina" ganhou popularidade após ser apresentada em debate eleitoral para a presidência da república promovido pela TV Bandeirantes e veiculado pela mesma emissora no dia 9 de agosto de 2018. ${ }^{26}$ O candidato Cabo Daciolo foi quem trouxe a Ursal a público ao atribuir a outro candidato, Ciro Gomes, uma possível relação com a suposta entidade. ${ }^{27}$ Posteriormente, a existência fictícia da Ursal foi reelaborada criativa e ludicamente em objetos de consumo (como camisetas e canetas), inúmeros memes, testes online (como “Qual seu nome na Ursal?”, “Que país da Ursal é você?”, “Quantos \% de Ursal existe em você?”) - e, no caso em análise, em uma paródia.

Recurso populares, e ao mesmo tempo sofisticado, da literatura, a paródia consiste na apropriação de determinada estrutura narrativa, repetida, mas em nova roupagem. No caso da composição musical, mantém-se a melodia e a harmonia da música, mas altera-se a letra. Conforme definição dada pelo próprio Hagemeyer,



O autor buscou no repertório de Chico Buarque de Hollanda a composição que serviu de base para sua paródia: o Fado Tropical foi transformado em Fado da URSAL. Neste, a Ursal entra em cena como musa comunista, deixando de lado a caricatura fantasmagórica que assombra o imaginário de certa comunidade (política, evangélica, conservadora) ao qual o candidato que a mencionou evoca.

Se em Fado Tropical o destino do Brasil é apresentado, de forma irônica, como o de ser tão somente "uma imenso Portugal", na paródia o destino do país é promover o sonho bolivariano de fazer da América Latina uma "grande Ursal!". Sonho esse cultivado por um narrador que se identifica como pertencente a um partido político que

\footnotetext{
${ }^{25}$ Disponível em: https://www.youtube.com/watch?v=eVNS_or1uJQ. Acesso em: 23 ago. 2019.

${ }^{26}$ Para mais informações sobre o debate e leituras sobre a chamada Ursal, ver: Rosa, Rezende \& Martins, 2018; Chagas, Modesto \& Magalhães, 2019.

${ }^{27}$ Disponível em: https://youtu.be/7ANqSdWvTlo. Acesso em: 23 ago. 2019.

${ }^{28}$ Disponível em: https://www.facebook.com/pg/parodiadasemana/about/?ref=page internal. Acesso em: 23 ago. 2019.
} 
só estaria "preocupado em conciliar, se aliar, reformar", mas que "no fundo" é comunista.

Uma pequena pausa na apresentação da composição para uma reflexão sobre o eu-lírico: trata-se de um comunista que na verdade se diz filiado a um partido reformista; logo, alguém que não assume sua identidade comunista se não pelo que guarda - ou seria melhor dizer, pelo que esconde "no fundo"? A deixa para essa interpretação não está apenas na escolha da imagem literária de um comunista escondido no armário, mas também no ter seu coração ardido quando fecha os olhos e vê o quanto a esquerda tem maltratado a musa bolivariana que é quem realmente importa. Seria o caso de um comunista em crise de identidade?

Deixando o desvio especulativo do eu-lírico comunista de lado, voltemos à composição. Ainda se dirigindo à musa bolivariana chamada Ursal, são convocadas a seu favor nomes importantes da esquerda latino-americana: Allende, Sandino, Che, Fidel, Marighella e Zapata. A escolha dos heróis que ajudarão a musa a cumprir o ideal bolivariano não é aleatória: estão listados todos que, guardados seus respectivos posicionamentos políticos, se filiaram a propostas socialistas/comunistas, seja no ideal, seja na implementação de ações políticas efetivas.

No Fado da Ursal o tempo histórico é suspenso para trazer para o contexto eleitoral brasileiro não o fantasma da unidade latino-americana, mas a realização de todos os projetos revolucionários tentados desde Simon Bolivar. Seria a eleição presidencial brasileira o momento de cumprimento da promessa messiânica de uma grande Ursal?

Unificar tempo e espaço, usar e abusar do anacronismo deliberado e reflexivo, reivindicar personagens históricos da experiência de esquerda latino-americana e transformar a paranoia da direita religiosa e conservadora em algo que não apenas é risível - mas que por meio do riso recupera sua potencialidade utópica - é algo que revela não apenas a criatividade artística do historiador, como também a boa articulação que fez da sua formação como professor e pesquisador especializado em história da América Latina na composição e interpretação de Fado da Ursal. Se todo sujeito que gosta de música é capaz de fazer paródias, há um um diferencial em paródias de cunho histórico, tal como as feitas por Hagemeyer. Elas são mais que uma resposta imediata a uma situação do presente, pois, tal como vemos na composição aqui destacada, há referências a personagens históricos que requerem determinada familiaridade com a disciplina. Nesse sentido, é o próprio autor quem menciona esse vínculo: 
Como professor de História, tendo trabalhado com a canção popular e as paródias no meu doutorado, eu não poderia deixar de ter consciência do tipo de apropriação simbólica que envolve esse tipo de trabalho. Tomar uma melodia conhecida do público e retrabalhar o sentido de sua letra de acordo com o sentido dos acontecimentos atuais, esse foi o sentido da criação do Paródia da Semana. (...) Ao observar que algumas das primeiras gravações da história da música popular nos Estados Unidos tratavam de assuntos atuais, como o desastre do navio Titanic em 1910, veio a ideia de realizar uma espécie de crônica semanal dos acontecimentos políticos que assolavam o país. ${ }^{29}$

Mais que uma reação sintomática a acontecimentos do momento, as paródias de Rafael Hagemeyer se constituem em projeto pensado e fundamentado histórico e teoricamente. Suas composições e interpretações remetem à sua trajetória como historiador e professor. Elas se articulam com a pesquisa de doutorado, mas também com o fato de ser professor de uma disciplina obrigatória no currículo de História da Universidade do Estado de Santa Catarina que se chama Laboratório de Imagem e Som. Por meio de suas paródias, é possível refletir sobre espectros do passado que reaparecem no presente, projetos revolucionários latino-americanos, usos políticos do passado e respostas imediatas que historiadores(as) podem manifestar articulando tanto sua expertise quanto o papel público que o historiador é requisitado a cumprir em tempos de barbárie. Acrescente-se que a referida paródia teve mais de 7 mil visualizações $^{30}$ e uma interação significativa por meio de curtidas e comentários - grau de popularidade que poucos historiadores brasileiros conseguem alcançar em tão pouco tempo com um artigo científico ou um livro autoral. Como o próprio autor reconhece em texto de apresentação da página, nada disso seria possível sem o advento das redes sociais. Essa ferramenta - cujo papel social, político e cultural no tempo presente não deve ser ignorado - é talvez uma das mais potentes que o historiador e o intelectual têm diante de si.

\section{A história que a história não conta e seus embates}

Um terceiro caso - no qual o historiador, à diferença dos casos anteriores, é um agente entre outros - emerge do universo das escolas de samba. Campeã do Carnaval do Rio de Janeiro em 2019, a Mangueira levou para a avenida "a história que a história não conta”, trazendo à tona memórias de negros, índios e pobres, invisibilizados por uma

\footnotetext{
${ }^{29}$ Disponível em: https://www.facebook.com/pg/parodiadasemana/about/?ref=page internal. Acesso em 25 ago. 2019

30 Em 12 de agosto de 2018 a página contava 7.373 visualizações. Disponível em: https://www.facebook.com/search/top/?q=fado\%20ursal\&epa=SEARCH_BOX. Acesso em: 23 ago. 2019.
} 
história que por muito tempo se dedicou apenas aos grandes vultos da nação. Conforme um dos compositores do samba-enredo, Luiz Carlos Máximo, afirmo: "Esse é o grande trunfo do enredo. A gente aprende na escola os heróis que na verdade não são os nossos heróis. Nossos heróis são os heróis da resistência, quem lutou pela liberdade e por todas as demandas sociais que a gente sempre está brigando" 31 .

Acionada na fala do compositor, a noção de demanda social é uma chave de reconhecimento da força política do samba-enredo. O tema elaborado pela escola procura historicizar o passado recente, questionando a maneira como este tem sido transmitido e buscando responder, assim, às demandas sociais por reconhecimento e por justiça. Tais anseios podem ser entendidos também como "reivindicações memoriais" e se referem a

passados traumáticos difíceis de assumir por parte das comunidades nacionais e que emanam de pessoas ou de grupos que não pertencem ao meio dos historiadores profissionais. $\mathrm{O}$ reconhecimento de uma dívida a saldar em relação ao passado parece, portanto, comum a essas reivindicações memoriais. $^{32}$

O samba-enredo - de autoria de Deivid Domênico, Tomaz Miranda, Mama, Marcio Bola, Ronie Oliveira, Manuela Oiticica e Danilo Firmino - faz uma crítica aos perigos de uma história que apaga, negligencia ou torna superficiais determinadas experiências e narrativas. A invisibilização de indígenas, o embranquecimento de personalidades negras (como Aleijadinho), a exaltação acrítica aos bandeirantes, os desaparecidos e torturados durante a ditadura militar (um dos carros alegóricos trazia a frase "Ditadura assassina"), o assassinato ainda impune de Marielle Franco ${ }^{33}$, e uma bandeira do Brasil estilizada, onde no lugar de "ordem e progresso" lia-se "índios, negros e pobres" são, entre outras, as questões levantadas pelo desfile. A Mangueira buscou alertar o grande público sobre a importância das muitas histórias, um equilíbrio que permite o reconhecimento de grupos invisibilizados, apontando os perigos de uma história única, como bem alertou Chimamanda Adichie ${ }^{34}$, permitindo o conhecimento do outro e de outros lugares.

\footnotetext{
${ }^{31}$ https://g1.globo.com/rj/rio-de-janeiro/carnaval/2019/noticia/2019/03/07/compositores-do-sambaenredo-campeao-dedicam-vitoria-ao-povo-da-mangueira.ghtml. Acesso em: 19 mar. 2019.

32 DELACROIX, Christian. "L'histoire du temps présent, une histoire (vraiment) comme les autres?" Tempo e Argumento, Florianópolis, v. 10, n. 23, p. 05 - 38, jan./mar. 2018.

${ }^{33}$ Socióloga, eleita vereadora do Rio de Janeiro em 2016, crítica da intervenção federal no Rio de Janeiro e da Polícia Militar, foi responsável por denúncias aos abusos de autoridade por parte de policiais contra moradores de comunidades carentes. Foi assassinada a tiros em 14 de março de 2018, junto de seu motorista, Anderson Pedro Mathias Gomes, no Rio de Janeiro.

${ }^{34}$ A escritora nigeriana Chimamanda Adichie usou o termo "história única" para criticar a construção distorcida de estereótipos de pessoas e/ou lugares, em sua palestra no evento Tecnology, Entertainment
} 
Duque de Caxias, considerado patrono do exército brasileiro, foi representado em um carro alegórico pisando em corpos ensanguentados, representando as vítimas da repressão militar durante o período imperial. O carro que apresentou a polêmica é assinado por professores de escola do Rio de Janeiro. A referência a Duque de Caxias é assinada por Tarcísio Motta, vereador no Rio pelo Psol e professor de história do Colégio Pedro II. ${ }^{35}$

Caxias tinha como propósito manter a unidade do território nacional durante o período regencial (1831-1840), atuando na repressão à revoltas populares, como Balaiada, no Maranhão, e à Revolução Farroupilha, no Sul do Brasil. Sua trajetória também está ligada à Guerra do Paraguai, onde atuou no comando das forças do Império, um confronto deixou um saldo de mortos que gira entre 130 mil e 300 mil pessoas. Uma publicação via twitter da assessoria de imprensa das Forças Armadas logo após o anúncio da vitória da Mangueira é entendida pela imprensa como uma resposta, apesar de não mencionar a escola: "tentativas de revisionismo acerca da figura do Duque de Caxias ocorrem de tempos em tempos, sem nenhuma base historiográfica" ${ }^{36}$.

Em outra alegoria, levou-se para o sambódromo a pichação do Monumento às Bandeiras, ocorrido em São Paulo em 2016. Os monumentos foram tingidos de tintas coloridas ocorreu logo depois do debate entre os candidatos à Prefeitura de São Paulo, naquele ano, em que foi abordado, dentre outros temas, o abandono da cidade. A pichação gerou reações diversas. O Instituto Victor Brecheret, voltado à obra do escultor, lamentou a violência contra a obra, apontada pela instituição como uma das mais importantes do país. Cabe apontar que as discussões geradas a partir do ato tiveram tamanha repercussão que chegaram a se transformar em questão da Olimpíada Nacional de História de $2017^{37}$. O episódio questiona a "liturgia auto consagradora do

and Design (TED), posteriormente disponibilizado em vídeo no site Youtube e amplamente divulgado nas redes sociais. Disponível em:

https://www.ted.com/talks/chimamanda adichie the danger_of a single story/transcript?language=pt.

Acesso em: 12 set. 2019.

35 Disponível em: https://oglobo.globo.com/rio/exercito-exalta-duque-de-caxias-no-twitter-apos-criticada-mangueira-ao-personagem-historico-23505253. Acesso em: 15 set. 2019.

36 Disponível em: https://oglobo.globo.com/rio/exercito-exalta-duque-de-caxias-no-twitter-apos-criticada-mangueira-ao-personagem-historico-23505253. Acesso em: 15 set. 2019.

${ }^{37}$ BAUER, Leticia. BORGES, Viviane. O patrimônio cultural e a história pública: observações sobre os embates contemporâneos. Revista NUPEM, Campo Mourão, v. 11, n. 23, p. 48-58, maio/ago. 2019 
poder" 38 que institui o que deve ser rememorado. Na leitura da Mangueira, os danos à obra foram apresentados como marcas do sangue derramado por heróis populares" 39 .

A crítica social alinhada às demandas sociais e a visibilização de personagens marginalizados não é novidade no carnaval brasileiro. Já nos anos 1960 a Salgueiro apresentou personagens pouco (ou nada) conhecidos, como Chica da Silva, Chico Rei e Zumbi dos Palmares. Em 2018, apenas para citar o exemplo do carnaval anterior, a Paraíso do Tuiuti, levou para avenida o enredo "Meu Deus, Meu Deus, Está extinta a Escravidão?”. A escola, que foi vice-campeã, mobilizou a atenção do público ao propor um samba-protesto que apontava o racismo e as reverberações da escravidão no presente. Uma das alas ironizava o caráter manipulador da mídia e das redes sociais e seu papel na formação dos manifestantes, chamados de "manifestoches". A respeito do desfile, Ana Maria Mauad, que o considerou um fenômeno de história pública do tempo presente, escreveu tratar-se de um exemplo do que ela chama de "atitude historiadora: a tomada de posse do passado comum para dar sentido ao presente e situar-se no fluxo do tempo futuro" 40 .

Esse diálogo entre o passado, o presente e o futuro também aparecem no enredo da Mangueira, que relaciona, por exemplo, as demandas por intervenção militar por parte de alguns grupos ao fato de terem aprendido a história de forma enviesada ${ }^{41}$. Chama a atenção o destaque dado, em reportagens que repercutiram o desfile, a consulta de "historiadores, livros e teses" 42 para tecer o polêmico enredo. "Para desenvolvimento do enredo, Leandro consultou historiadores como Luiz Antonio Simas. E tem passado horas debruçado sobre uma infinidade de teses e livros", destacou uma delas, de certa forma ratificando a autoridade profissional do historiador como intérprete legítimo do passado. Para Simas, historiador e co-autor do Dicionário de História Social do Samba, entre outros trabalhos, “o enredo da Mangueira 'é da maior relevância' por lançar um olhar crítico sobre a ideia do protagonismo histórico e destacar personagens do povo -

${ }^{38}$ CANCLINI, Néstor Garcia. Culturas híbridas: estratégias para entrar e sair da modernidade. São Paulo: Editora da Universidade de São Paulo, 2013.

39 Disponível em: https://veja.abril.com.br/entretenimento/mangueira-faz-desfile-povoado-de-criticas-ahistoria-oficial-do-brasil/. Acesso em: 15 set. 2019.

${ }^{40}$ MAUAD, Ana Maria. "O Carnaval da História Pública”. In: ALMEIDA, Juniele Rabêlo; MENESES, Sonia (org.). História Pública em Debate: patrimônio, educação e mediações do passado. São Paulo: Letra e Voz, 2018.

41 Disponível em: https://oglobo.globo.com/rio/enredo-da-mangueira-contara-lado-da-historia-do-brasilna-sapucai-22811315. Acesso em: 16 set. 2019.

42 Disponível em: https://oglobo.globo.com/rio/enredo-da-mangueira-contara-lado-da-historia-do-brasilna-sapucai-22811315. Acesso em: 16 set. 2019. 
ligados ao cotidiano de qualquer um - que fizeram parte de lutas históricas"43. O historiador cita ainda Walter Benjamin para corroborar seu argumento, apelando à proposição do filósofo sobre a necessidade de "escovar a história a contrapelo". ${ }^{44}$

Além de Simas, outros historiadores e historiadoras foram chamados para comentar a escolha do enredo e sua importância na atual conjuntura brasileira. A historiadora Heloisa Starling, professora da Universidade Federal de Minas Gerais (UFMG), aponta o diálogo estabelecido entre a temática abordada e as demandas do presente, atento às "questões que estão na ordem do dia": "A História é uma coisa muito viva. Você sempre viaja para o passado com as perguntas do presente. E as perguntas que ele está fazendo são questões de hoje, como a busca por mulheres que tiveram protagonismo no Brasil" 45 .

A ANPUH, Associação Nacional de História, publicou em seu site um texto intitulado "Estação Primeira de Mangueira" 46 , no qual - apropriadamente - aponta que a ausência de historiadores entre os comentadores do carnaval criou a falsa ideia de que os temas ligados aos sujeitos marginalizados não fazem parte do temário do historiador em atividade nos dias de hoje. O texto ressalta que a Mangueira fez o que muitos professores de história fazem em seus cursos: "contar a história de baixo para cima e aclamar com orgulho personagens heróicos da história do Brasil, com Dandaras, Cariris, Malês, Dragões do Mar, Luizas Mahins, Esperanças Garcias e Marielles”. De fato, os historiadores há décadas trabalham com os temas trazidos pela escola, na escala que lhes compete. Foi também marcante a presença de documentos e textos resultantes de pesquisas de historiadores na construção do desfile. Continua o texto, assinado pelas historiadoras e professoras de História do Brasil Hebe Mattos, Martha Abreu e Keila Grinberg:

É importante esclarecer que a história do Brasil cantada pela Mangueira na avenida vem sendo exaustivamente pesquisada, estudada e ensinada por historiadores dos quatro cantos do país desde pelo menos os anos 1980. Documentos de arquivo e textos de professores e historiadores fizeram parte diretamente do desfile. Há uma sólida lista de livros, artigos e teses a

\footnotetext{
${ }^{43}$ Disponível em: https://www.bbc.com/portuguese/brasil-47409435?ocid=socialflow_facebook\%20. Acesso em 20 set. 2019.

${ }^{44}$ Disponível em: https://www.bbc.com/portuguese/brasil-47409435?ocid=socialflow_facebook\%20 Acesso em 20 set. 2019.

${ }^{45}$ Disponível em: https://www.bbc.com/portuguese/brasil-47409435?ocid=socialflow_facebook\%20 Acesso em 20 set. 2019.

${ }^{46}$ Disponível em: https://anpuh.org.br/index.php/2015-01-20-00-01-55/noticias2/anpuhresponde/item/5105-estacao-primeira-de-mangueira. Acesso em: 25 mai. 2019.
} 
fundamentar a narrativa da Escola, alguns citados pelo carnavalesco na apresentação do enredo. (...)

O vitorioso enredo de Leandro Vieira tornou evidente para o grande público o que especialistas e os sambistas há muito já sabiam: as escolas de samba são, e sempre foram, lugar privilegiado de produção de pensamento crítico sobre a história do Brasil. (...) Os profissionais de história não estão entre os comentaristas da TV, mas estão no mundo do samba. Não há dúvidas de que grande parte dos carnavalescos, compositores, cenógrafos, e todos os envolvidos na produção dos desfiles manjam mesmo, e muito, de História. ${ }^{47}$

Extrapolar as narrativas oficiais, mostrando as trajetórias de personagens invisibilizados ${ }^{48}$, é algo que no Brasil a história tem procurado fazer pelo menos desde os anos 1980, embasada pelas possibilidades trazidas pela história social e pela história cultural e pela adoção de metodologias como a história oral. A história daqueles que não faziam parte da história tem mostrado as potencialidades dos sujeitos marginalizados para a compreensão de práticas sociais e culturais até então igualmente invisibilizadas. O samba da Mangueira corrobora essa história até então majoritariamente restrita aos muros acadêmicos, mostrando o protagonismo de lideranças negras e indígenas ajuda a desestabilizar construções pejorativas, como a ideia de que o Brasil teria herdado "a indolência dos indígenas e a malandragem dos africanos" ${ }^{\text {49 }}$. A potência da história do tempo presente e da história pública está em incluir as intervenções do presente na discussão acerca da produção de sentidos históricos para além da academia, problematizando e desconstruindo tentativas de instituir uma história única em nome de um coletivo imaginário baseado em uma suposta identidade comum.

\section{História oral: $\mathbf{O}$ testemunho como resposta rápida}

A crônica, a paródia, o enredo da escola de samba são formatos para os quais a crítica social, mordaz, irônica, pícara, não é estranha. Da mesma forma, a ação imediata, impelida pela denúncia, não é estranha para um método, uma prática e uma abordagem

47 Disponível em: https://anpuh.org.br/index.php/2015-01-20-00-01-55/noticias2/anpuhresponde/item/5105-estacao-primeira-de-mangueira. Acesso em: 25 mai. 2019.

${ }^{48}$ Entre eles Cunhambebe, líder dos tamoios na resistência à ocupação portuguesa no litoral do sudeste no século XVI; Luiza Mahin, ex-escrava que teria se tornado uma liderança nas lutas contra a escravidão na Bahia no início do século XIX; e Chico da Matilde, um jangadeiro negro no Ceará que ficou conhecido como o Dragão do Mar, após liderar uma paralisação de jangadeiros, negando-se a fazer o transporte dos navios negreiros que chegavam no porto, no século XIX.

49 "Candidato à vice-presidência da República na chapa de Jair Bolsonaro (PSL) nas eleições 2018, o general da reserva Hamilton Mourão disse nesta segunda-feira, 6, que o Brasil "herdou a cultura de privilégios dos ibéricos, a indolência dos indígenas e a malandragem dos africanos". A declaração foi feita em um evento em Caxias do Sul, no Rio Grande do Sul, quando Mourão falava sobre as condições de subdesenvolvimento do País e da América Latina". Disponível em: https://politica.estadao.com.br/noticias/eleicoes,mourao-liga-indio-a-indolencia-e-negro-amalandragem,70002434689. Acesso em: 26 abr. 2019. 
bem conhecida dos historiadores: a história oral, que é o método que orienta o quarto caso em análise.

O pendor interventivo da história oral (que convive com outros entendimentos, como o da simples técnica de documentação) aviva a referência a trabalhos como o da socióloga francesa Elisabeth Burgos em colaboração com a ativista guatemalteca Rigoberta Menchú, que rendeu a esta um livro - hoje controverso - de popularidade mundial $^{50}$ e um prêmio Nobel da Paz. Ou então à tradição engajada da história oral acadêmica que a mexicana Eugenia Meyer ajudou a introduzir no Brasil, em suas aulas ministradas no país ainda na década de $1970^{51}$. Ou, ainda, a produtos editoriais que desejaram, antes de fornecer uma análise aprofundada de fenômenos contemporâneos, espargir as vozes de quem os protagonizava e assistia, como no caso da primeira marcha do Movimento de Trabalhadores Rurais Sem Terra ${ }^{52}$.

Mais recentemente, a aliança entre a história pública e a história oral têm não somente reforçado trabalhos socialmente comprometidos, mas possibilitado um avanço formal e conceitual no tratamento e no entendimento da narrativa como um meio de, a um tempo, promover intervenções e construir conhecimento crítico no tempo presente. Valoriza-se, particularmente, a capacidade de a história oral ser um meio privilegiado para oferecer respostas rápidas a demandas sociais pelo registro e pela análise histórica de acontecimentos contemporâneos, sobretudo aqueles imprevisíveis, como conflitos sociais e desastres naturais; um meio privilegiado de reconhecer e preservar as narrativas de pessoas e grupos em situações de sofrimento e de vulnerabilidade de várias ordens, situações que passam a ser constitutivas de suas identidades pessoais e sociais. Aproxima-se portanto de uma ação historiadora que, como Jean-Pierre Rioux dizia ainda no início dos anos 1990, aprendeu com o que de melhor a ação jornalística podia ensinar: "na escolha de seus temas, impelida pela atualidade e submetida à pressão das testemunhas e dos atores que desejam que sua experiência seja rememorada numa produção ou numa co-produção históricas" ${ }^{, 53}$.

\footnotetext{
${ }^{50}$ BURGOS, Elisabeth. Meu nome é Rigoberta Menchú e assim nasceu minha consciência. Rio de Janeiro: Paz e Terra, 1993.

${ }^{51}$ FERREIRA, Marieta de Moraes. Eugenia Meyer - Entrevista. Revista Brasileira de História, v. 33, n. 65, p. 413-431, 2013.

${ }^{52}$ SANTOS, Andrea Paula dos; RIBEIRO, Suzana Lopes Salgado; MEIHY, José Carlos Sebe. Vozes da marcha pela terra. São Paulo: Editora Loyola, 1998.

${ }^{53}$ RIOUX, Jean-Pierre. "Entre história e jornalismo". In: CHAVEAU, Agnès; TÉTART, Philippe (org.) Questões para a história do presente. Bauru, SC: Edusc, 1999. p. 119-26.
} 
Existem alguns casos interessantes a se observar, de iniciativas nas quais as estratégias ligadas à história oral são mobilizadas e apropriadas de maneira muito distinta, mas com o propósito comum de impactar, em caráter imediato, a memória pública. A associação estadunidense de história oral, por exemplo, tem valorizado e apoiado institucionalmente a capacidade reativa da história oral diante de crises. No ano de 2006, a associação criou o Emerging Crises Oral History Research Fund, um fundo de pesquisa voltado a apoiar investigações sobre situações de crise - projetos com necessidades emergenciais, que não poderiam esperar por outro tipo de financiamento. A apresentação do fundo assume que:

As pesquisas em história oral incluem projetos importantes que tratam de situações de crise atuais tanto nos Estados Unidos quanto internacionalmente, incluindo guerras, desastres naturais, repressão política, econômica e/ou étnica, ou outros eventos atuais em proporção de crise. Estudiosos que conduzem pesquisas de história oral nesses tipos de projeto costumam começar a entrevistar seus informantes após semanas ou meses da crise, ou mesmo ao longo do desenrolar do evento crítico. Obter financiamento para esse tipo de pesquisa costuma ser difícil, por conta do demorado calendário de chamadas da maior parte das organizações financiadoras. ${ }^{54}$

A variedade dos temas dos projetos recipientes nas chamadas anuais do fundo demonstram a amplitude das situações de crise nas quais a história oral pode adquirir relevância pública na mobilização em situações urgentes: a exploração do trabalho e as condições laborais de mulheres migrantes na $\mathrm{China}^{55}$; a participação na primavera árabe; os refugiados climáticos que tiveram de deixar seus territórios em Louisiana, em função da destruição frequente de suas propriedades por enchentes e furacões; os movimentos contra a violência policial; e assim por diante. O projeto mais recente, a quem o financiamento foi outorgado em 2018, é uma "História oral dos Furacões Irma e Maria: Uma crise social, cultural e ambiental em Porto Rico e nas Ilhas Virgens Americanas". ${ }^{56}$ No ensaio introdutório de um livro que organizou com Stephen Sloan justamente sobre o papel da história oral em situações de crise ${ }^{57}$, Mark Cave assinalou o fenômeno de aceleração e encurtamento do intervalo entre a ocorrência de tragédias e situações de crise e a ação de pesquisadores de história oral em sua documentação.

\footnotetext{
54 "Emerging Crises Oral History Research Fund". Disponível em: https://www.oralhistory.org/award/emerging-crisis-research-fund/. Acesso em: 07 ago. 2019.

55 Este projeto, especificamente, teve como base narrativas de mulheres com doenças ocupacionais de uma fábrica de baterias. Resultou em um curta-metragem intitulado Red Dust. Disponível em: https://www.cultureunplugged.com/storyteller/Karin_Mak\#/myFilms. Acesso: 07 ago. 2019.

${ }^{56}$ Não estão disponíveis os resumos ou os projetos completos; tampouco se localizaram os resultados de todos os projetos. Por essa razão, mencionamos apenas uma seleção aleatória dos mesmos.

${ }^{57}$ CAVE, Mark; SLOAN, Stephen M. Listening on the Edge: Oral History in the Aftermath of Crisis. Oxford: Oxford University Press, 2014.
} 
Identificou algumas das preocupações ativadas por esse tipo de trabalho (o impacto psicológico da entrevista sobre os entrevistados, sobretudo), mas valorizou o papel da metodologia e de seus pesquisadores em contribuir para que as comunidades afetadas reconstituam seu sentido identitário a partir dos restos deixados após crises e tragédias.

O cenário de ataque aos direitos sociais e individuais e o desmonte dos sistemas de proteção ao cidadão e à vida em sociedade, em galopante agravamento no Brasil desde o golpe de 2016, tem incitado historiadores a entrever na narrativa pessoal, instanciada a partir de experiências coletivas de conflito e violência, um lugar de resistência. Conjuntos de narrativas sobre o presente e o passado recente refazem-se, e renovam sua função, enquanto espécies de construtos simbólicos nos quais os sentidos do democrático, do público e do comum podem ser preservados; que constituem tanto um modo incisivo de oposição a tais ataques e desmontes quanto um tipo de reserva de memória cultural capaz de garantir a persistência de valores desafiados e por vezes diretamente torpedeados por medidas governamentais agressivas e antidemocráticas.

Tomemos o caso de um projeto recente, baseado em entrevistas, que parece - entre outras finalidades - induzir a criação de reservatórios de memórias e de representações sociais em risco. Narrativas em movimento - Do "Escola Sem Partido” à "Educação Democrática": História pública e trajetórias docentes é o título da dissertação de mestrado em História de Renan Rubim Caldas, defendida em 2018 na Universidade Federal Fluminense, para a qual o autor se mobilizou a partir do candente debate público sobre a profissão docente - debate persistente no tocante às condições de trabalho do professor, que ganhou novos contornos, em um contexto de ascensão conservadora no qual o movimento "Escola sem Partido" (compreendido por Caldas como um "antimovimento social") se gestou.

Lidando com o imediato como sua dimensão temporal por excelência, Caldas analisou as narrativas públicas construídas em torno do "Escola sem Partido" e do movimento social "Professores Contra o Escola Sem Partido" - assim chamado pelo autor, que deslinda o papel do movimento na defesa da educação democrática. Aos professores de História do ensino básico, Caldas atribui um duplo compromisso com a história pública: eles seriam agentes da disseminação e da construção crítica de saberes históricos, na sala de aula, mas também seriam "sujeitos históricos intervindo na realidade social, política e cultural em que vivem, ou seja, em que atuam como 
intelectuais públicos e transformadores em outros espaços públicos da sociedade, para além do espaço acadêmico" $" 58$.

Caldas acrescenta sua própria camada a essa "atitude historiadora" - que é individual e coletiva - quando documenta as histórias de vida de docentes de História do ensino básico, aceitando a história oral como um método de investigação e ação, um método narrativo e participativo, que faculta e convida à plena tomada da palavra por parte de sujeitos históricos. Longe de arremedar o consagrado nicho da história oral da profissão docente, de tom não raro "celebrativo" e nostálgico, Caldas assume as narrativas como um espaço de discussão sobre a - e, por conseguinte, de exercício da função social da disciplina histórica e as responsabilidades sociais do historiador e do professor de História. Assim, Caldas nos reafirma que, para além das possibilidades de utilização de novos meios, suportes e linguagens para elaboração de questões que estão na ordem do dia, também a pesquisa especializada, a sala de aula e os métodos consolidados de investigação (a história oral) e de difusão (uma dissertação de mestrado) seguem sendo instrumentos potentes. Quando olham para as demandas sociais, configuram narrativas públicas, indispensáveis em sua condição pública, para a reconstrução e revalidação coletiva - como neste caso - dos significados da profissão docente.

\section{Algumas considerações, para encerrar sem conclusão}

Esses casos, por diversos que sejam, tangenciam as relações entre demandas sociais, história do tempo presente e história pública, articuladas com avanços epistemológicos e ontológicos da História. As formas tradicionais de manifestação da comunidade de historiadores sobre questões polêmicas pautadas pelo seu tempo costumavam, no passado, se dar por meio de petições, cartas de adesão, artigos de jornais, em suma, por formatos que mantinham vínculo com a tradição escrita e com o domínio que tinha sobre as etapas da produção.

Treinado para construir uma monografia, uma tese ou uma dissertação, para além de discursar e apresentar oralmente os resultados de sua pesquisa, com as novas tecnologias o historiador se vê na iminência de ter que produzir narrativas mediado por outras linguagens que não a escrita. Ao fazer isso, não apenas leva sua expertise para a

58 CALDAS, Renan Rubim. Narrativas em movimento - do "Escola sem Partido" à "Educação Democrática": História Pública e trajetórias docentes. Dissertação (Mestrado em História). Universidade Federal Fluminense. Niterói, 2018 
nova plataforma que escolheu, como também é moldado pelos limites e potencialidades que o meio utilizado impõe - seja ele o cinema, a música ou a crônica literária. Isso não apenas amplia o raio de ação e repercussão do trabalho do historiador como traz novos desafios técnicos e epistemológicos para a comunidade científica.

A incorporação da arte, da história oral, da música, do filme e da fotografia na oficina do historiador ajudou a ampliar, refinar e fortalecer a história enquanto ciência. Seria diferente se incorporássemos os memes, as redes sociais, os blogs, os stories? O texto do historiador já passou pelas narrativas monográficas, pelos ensaios, pelas páginas de jornais. Perderia seu rigor enquanto erudição, posicionamento crítico e responsável se formatado em paródias, crônicas, exposição, organização de acervo, documentários ou games educativos?

Não é o caso de abrir mão da crítica rigorosa, de uma história fundamentada em fontes, arquivos e métodos, mas de reavaliar os limites desse tipo de narrativa no mundo contemporâneo e propor, junto a eles, novas formas e estilos de apresentação do trabalho do historiador. Tampouco se trata de trocar a avaliação dos pares pelo número de likes nas redes sociais ou a popularidade da manifestação dos historiadores, mas de colocar as regras e métodos apreendidos na formação em formatos capazes de chegar a públicos com pouco - se não nenhum - conhecimento acerca de como funciona o trabalho do pesquisador da área de história. Dar a esse público ampliado a possibilidade de conhecer parte da nossa labuta, se posicionar sobre ela e, no limite, desejar conhecer as outras modalidades de narrativa e de reflexão da comunidade historiográfica.

A enunciação pública da relação entre os homens e o tempo não implica colocar a história a serviço dos movimentos sociais, construindo uma história hagiográfica da luta operária, feminista, ambiental, e assim por diante - mas abrir a história para refletir criticamente com e sobre os movimentos sociais e as diferentes formas de organização da sociedade civil. Trazer para a universidade suas demandas e devolvê-las a partir da análise rigorosa - de forma a estimular os sujeitos e grupos à reflexão sobre as dinâmicas temporais de suas reivindicações, assim como o historiador a ampliar e refinar seu repertório crítico, temático e analítico - é possível, dentro de um esforço que prime pela horizontalização da produção do conhecimento histórico.

A sobrevivência da história, como área de conhecimento legítima e reconhecida científica e socialmente, só estará em perigo se, diante dos desafios de se arriscar quando questões candentes do presente exigem posicionamento e análise, for preferível ficar no silêncio esperando que historiadores do futuro ofereçam explicações para o que 
vivemos no presente. É fundamental que a comunidade de estudiosos não se omita sobre os usos e abusos do passado no tempo presente, sobre as violências, censuras, golpes e articulações que irrompem de tempos em tempos e, principalmente, como eles estão à espreita na atualidade. É preciso fazer isso com respeito e com seriedade, mas também com criatividade. As ferramentas virtuais, as redes sociais e os múltiplos recursos narrativos e tecnológicos disponíveis são aliados poderosos na abertura para uma história que não se esconda sobre o manto da imparcialidade e da cientificidade que a tornou notória no século XIX. Que toda história possa ser pública e presente no tempo em que habita é uma tarefa que se impõe às nossas gerações.

Data de submissão: 20/12/2019

Data de aceite: 27/07/2020 


\section{Referências Bibliográficas}

BAUER, Leticia. BORGES, Viviane. O patrimônio cultural e a história pública: observações sobre os embates contemporâneos. Revista NUPEM, Campo Mourão, v. 11, n. 23, p. 48-58, maio/ago. 2019.

BELAVICQUA, Piero (org.) A che serve la storia? I saperi umanistici alla prova della modernità. Roma: Donzelli Editore, 2011.

BURGOS, Elisabeth. Meu nome é Rigoberta Menchú e assim nasceu minha consciência. Rio de Janeiro: Paz e Terra, 1993.

CALDAS, Renan Rubim. Narrativas em movimento - do "Escola sem Partido" à "Educação Democrática": História Pública e trajetórias docentes. Dissertação (Mestrado em História). Universidade Federal Fluminense. Niterói, 2018.

CANCLINI, Néstor Garcia. Culturas híbridas: estratégias para entrar e sair da modernidade. São Paulo: Editora da Universidade de São Paulo, 2013.

CARVALHO, B. L. P.; TEIXEIRA, A. P. T. (org.) História pública e divulgação de história. São Paulo: Letra e Voz, 2019.

CAVE, Mark; SLOAN, Stephen M. Listening on the Edge: Oral History in the Aftermath of Crisis. Oxford: Oxford University Press, 2014.

CHAGAS, Viktor; MODESTO, Michelle; MAGALHÃES, Dandara. "O Brasil vai virar Venezuela: Medo, memes e enquadramentos emocionais no whatsapp pró-Bolsonaro". Esferas, n. 14, 2019.

DELACROIX, Christian. "L'histoire du temps présent, une histoire (vraiment) comme les autres?" Tempo e Argumento, Florianópolis, v. 10, n. 23, p. 05 - 38, jan./mar. 2018.

DELGADO, Lucilia de Almeida Neves; FERREIRA, Marieta de Moraes. "História do tempo presente e ensino de História". História Hoje, v. 2, n. 4, p. 19-34, 2013.

DUMOULIN, Olivier. O papel social do historiador. Da cátedra ao tribunal. Belo Horizonte: Autêntica, 2017.

FERREIRA, Marieta de Moraes. "Demandas sociais e a história do tempo presente". In: Varella, F. et al. (org.) Tempo presente \& usos do passado. Rio de Janeiro: Ed. FGV, 2012. p. 101-124.

FERREIRA, Marieta de Moraes. Eugenia Meyer - Entrevista. Revista Brasileira de História, v. 33, n. 65, p. 413-431, 2013.

GUlDI, Jo; ARMITAGE, David. The History Manifesto. Cambridge: Cambridge University Press, 2014.

HARTOG, François. Regimes de historicidade: presentismo e experiências do tempo. Belo Horizonte: Autêntica, 2013. 
HERMETO, Miriam; LIMA, Ricardo. "A história no palco". Revista de História da Biblioteca Nacional, n. 31, p. 60-3, 2008.

MAUAD, Ana Maria. "Imagens que faltam, imagens que sobram: práticas visuais e cotidiano em regimes de exceção (1960-1980)". Estudos Ibero-Americanos, v. 43, p. 397-413, 2017.

MAUAD, Ana Maria. "O Carnaval da História Pública”. In: ALMEIDA, Juniele Rabêlo; MENESES, Sonia (org.). História Pública em Debate: patrimônio, educação e mediações do passado. São Paulo: Letra e Voz, 2018. p. 227-36.

MORAES, José Geraldo Vinci; LIMA, Giuliana Souza de. "Entrevista com professor Arnaldo Daraya Contier”. Revista de História, n. 157, p. 173-192, 2007.

RIOUX, Jean-Pierre. "Entre história e jornalismo". In: CHAVEAU, Agnès; TÉTART, Philippe (org.) Questões para a história do presente. Bauru, SC: Edusc, 1999. p. 11926.

ROSA, Pablo Ornelas; REZENDE, Rafael Alves; MARTINS, Victória Mariani de Vargas. "As consequências do etnocentrismo de Olavo de Carvalho na produção discursiva das novíssimas direitas conservadoras brasileiras". Revista NEP, v. 4, n. 2, p. 164-203, 2018.

SANTOS, Andrea Paula dos; RIBEIRO, Suzana Lopes Salgado; MEIHY, José Carlos Sebe. Vozes da marcha pela terra. São Paulo: Editora Loyola, 1998.

SANTHIAGO, Ricardo. "História pública e autorreflexividade: da prescrição ao processo". Tempo e Argumento, Florianópolis, v. 10, n. 23, p. 286 - 309, jan./mar. 2018.

SANTHIAGO, Ricardo. "Duas palavras, muitos significados: Alguns comentários sobre a história pública no Brasil”. In: MAUAD, Ana Maria; ALMEIDA, Juniele Rabêlo de; SANTHIAGO, Ricardo (org.). História pública no Brasil: Sentidos e itinerários. São Paulo: Letra e Voz, 2016. p. 23-36.

SAUVAGE, Pierre. "Uma historia del tempo presente". Historia Critica, n. 17, p. 5970, 1998.

TOSH, John. Why History Matters. New York: Palgrave Macmillan, 2008.

TYRRELL, Ian. Historians in Public: The Practice of American History, 1890-1970. Chicago / London: The University of Chicago Press, 2005. 